\title{
USE OF INDIGENOUS ISOLATES OF METARHIZIUM, ISARIA AND BEAUVERIA AS POTENTIAL BIO-CONTROL AGENTS AGAINST Sitophilus oryzae UNDER LABORATORY CONDITIONS
}

\author{
Saif-Ur-Rehman ${ }^{1}$, Nazeer Ahmed ${ }^{2}$, Altaf Hussain Lahori ${ }^{3}$, Ji-nian Feng ${ }^{*}$ and Dun Wang ${ }^{*}$
}

\author{
${ }^{1}$ Department of Entomology, Northwest A\&F University, Yangling, Shaanxi,712100, P.R. China; ${ }^{2}$ Department of \\ Agriculture Science, University of Swabi, KP-Pakistan; ${ }^{3}$ Department of Environmental Sciences, Sindh Madressatul \\ Islam University, Karachi. \\ *Corresponding author’s e-mail: wanghande@yahoo.com; jinianf@nwsuaf.edu.cn
}

\begin{abstract}
Entomopathogenic fungi (EPF) are suggested as a new class of alternates followed by Synthetic chemical control of the insect pests .Virulence of seven EPF isolates, four strains of Metarhizium \{(Qin-08, Qin-13, Qin-18 and ME-38 (LT-178)\}, two of Isaria \{ME-33 (ILT-01), Yulin-5 (IYL-01) \} and one of Beauveria bassiana (Qin-21) were assessed against the adults of Sitophilus oryzae under laboratory conditions, firstly at single conidial concentration $\left(1 \times 10^{8} \mathrm{ml}^{-1}\right)$ by immersion and the food mix methods. Qin-21, ME-33 and Qin-18 caused significantly highest mortality of S.oryzae at immersion methods (100, 100 and $98 \%$ ), followed by food mix method to $100,84.16$ and $91.66 \%$ respectively. Yulin-5 was the least effective, showing significantly the lowest mortality at food mixed (32.49\%) and immersion methods $(40.20 \%)$ respectively. Hence, the immersion method was found to be most effective, resulting the higher mortality rate of $S$. oryzae in comparison to food mix method, in all tested fungal isolates. Secondly, we screened out the most effective isolates for multiple dose comparison i.e., $1 \times 10^{4}$ to $1 \times 10^{7}$ conidia $\mathrm{ml}^{-1}$ by immersion method only. The isolate ME-33 resulted in $100 \%$ mortality of the pest at higher conidial dose as compared to Qin-21 and Qin-18 which showing 80 and 64.64\% mortality respectively. The $\mathrm{LT}_{50}$ was observed to be 3.63, 4.17 and 8.58 days in ME-33, Qin-21 and Qin-18, respectively at the highest conidial concentration $\left(1 \times 10^{7} \mathrm{ml}^{-1}\right)$. ME-33 isolate with the highest mortality and lowest $\mathrm{LT}_{50}$ at conidial concentration $1 \times 10^{7} \mathrm{ml}^{-1}$ proved to be most effective for the control of $S$. oryzae. So these fungal islotes could be a better alternative for the management of $S$. oryzae.
\end{abstract}

Keywords: Biological control, Entomopathogenic fungi, Pathogenicity, Sitophilus oryzae.

\section{INTRODUCTION}

Cereals are one of the essential sources of direct intake of calories for humans and also as major feed of animals. Cereals also afford a wide range of food components and nutrients like phyto-chemicals (Liu, 2007). Grains are attacked by a diversity of different insect pest's species during their storage. The Post-harvest losses caused by these insects are estimated to be up to 20\% or more in developing countries (Phillips and Throne, 2010; Rojht et al., 2010; Stejskal et al., 2015). The majority of the control measures against the storage pests mostly rely on application the synthetic residual chemical based insecticides, which are used at the time of their storage for long-term protection. In addition, various toxic fumigants, such as phosphine, are also applied as control measures (Hertlein et al., 2011). However, only a limited number of chemicals are commercially registered against the storage product pests (Yacoub and Nickolas, 2017).

Indiscriminate and un-judicial use of these types of chemicals have been restricted due to their toxicity, human health concerns, need to protect the environment, overall safety concerns, besides to their harmful influence on non-target organisms (Boyer et al., 2012; Yacoub, 2018). In addition, there is a problem of resistance development in insects to these different synthetic chemical insecticides which are recently being practiced (Butt et al., 2006). Fungi invading dead insects are called saprophagous, while fungi infecting the living insects are identified as entomophagous (Hibbett $e t$ al., 2007). Out of 1.5-5.1 million fungi species globally (Leger and Wang, 2010), Approximately 750-1000 fungi are entomopathogens, distributed in about 100 genera (Barra et al., 2013). Among various insect pests of stored commodities, the Rice weevil, Sitophilus oryzae (Coleoptera: Curculionidae) is considered a most notorious pest specie of the storage commodities worldwide (Kaur et al., 2014). The adults of S.oryzae feed on grains while larvae prefer to feed inside the grain kernels and are responsible for both the quantity and quality losses of rice grain in stores (Kavallieratos et al., 2014; Nguyen et al., 2016). Weevils Population has developed the resistance against many chemical pesticides as well as fumigants which is commonly applied against the storage pests (Butt et al., 2006; Ramanujam et al., 2014).

Recently, more than 700 species and 90 genera of fungi were observed for infecting insects (Batta, 2008; Ramanujam et al., 2015; Maina et al., 2018). Most of these genera belong to 
family Deuteromycetes and Entomophthorales (Lord, 2007). Beauveria bassiana sensulato (Balsamo) Vuillemin (Ascomycota: Hypocreales) is used for the organization of stored products pests (Batta, 2005). B. bassiana has been reported as highly effective beside the major stored-product insect's viz., S. oryzae, $R$. dominica, and T. castaneum (Kaur et al., 2014; Kavallieratos et al., 2014; Nguyen et al., 2016). The EPF application is relatively safe approach against the coleopteran pest for the protection of stored items. Use of EPF for the control of $S$. oryzae is very rare and only few studies were conducted with the fungi Metarhizium anisopliae and Beauveria bassiana for the management of $S$. oryzae (Sanchez-Rodriguez et al., 2017; Pedrini et al., 2007). EPFs penetrate the insect body via cuticle, causing insect mortality, Fungi then inside insect body germinate and recycle on the cadavers, thus returning more inoculums to the stored-product system (Tadele and Pringle, 2007; Zhang et al., 2008; Stephou et al., 2012; Ortiz-Urquiza and Keyhani, 2013; Mandira et al., 2018). The present study indicated that selection of the virulent isolates was the most important in using entomopathogenic fungi for biological control of $S$. oryzae. The objective of present work was to investigate the pathogenicity of seven entomopathogenic fungi isolates such as Metarhizium anisopliae (Qin-08, Qin-13, Qin-18 and ME38 (LT-178), two of Isaria cateniannulata ME-33 (ILT-01), Yulin-5 (IYL-01) and one Beauveria bassiana (Qin-21), against the adults of $S$. oryzae under laboratory conditions.

\section{MATERIALS AND METHODS}

Insect culture: The Preliminary Population of S. oryzae was collected from insect-infested rice store at Yangling, Shaanxi Province (China). The stock was maintained under the laboratory conditions at Insect Related Resources (LIRR), Northwest A \& F University (NWAFU). The test insects were reared at $28^{\circ} \mathrm{C}$ with $\mathrm{RH} 65 \%$ (Tadesse and Subramanyam, 2018), in 2-liter glass jars having 1000-g rice grains free from any contamination. The transparent glass jars were covered with a piece of fine muslin's cloth. Two weeks later, original adults from the jars were removed out. The jars were observed daily and the same aged newly emerged 30 adults were used each for all series of bioassays.

Source of fungal isolates: Entomopathogenic fungi isolates were provided by Laboratory of insect related resources (LIRR) College of Plant Protection, Northwest A\&F University (Table 1).

Preparation of fungal conidia: For preparation the fungal suspensions of the seven fungal isolates, single spore isolates were cultured on Sabouraud-dextrose-yeast extract agar medium (SDAY) with 3.5-4 mm depth. The petri plates then kept in incubator for the period of two weeks, and the plates were without Para film lid sealing and by putting them in total darkness. They were put on $26^{\circ} \mathrm{C}$ and then shifted it in incubator with the relative humidity of (RH) $70 \%$ for a week more with 14:10 light and dark period. Sterilized spatula was used for the conidial harvesting at once, Prior to use in sterile $0.02 \%$ Tween 20 (Tianjin Guangfu Fine Chemical Research Institute, Xi'an, China). and then vortexed for two minutes. To minimize the Tween influence, fungal suspensions stock solution was diluted with sterilize $\mathrm{ddH}_{2} \mathrm{O}$. Concentrations of conidial suspensions were adjusted from $1 \times 10^{4}$ to $1 \times 10^{8}$ conidia $\mathrm{ml}^{-1}$ by using an improved-Neubauer hemocytometer (Lauda-Konigshofen, Germany) with a magnification which range $20 \mathrm{X}$ by the use of inverted microscope (Nikon Eclipse TE-2000-S Japan). Germination rate of conidia for all the tested isolates were assessed by planting the conidia 100 microliter in a $10^{7}$ conidia ml-1 suspension with a quarter ratio of SDAY at $26 \pm 2$ in a complete darkness (Inglis et al., 1997). Initial pathogenicity assay for EPF isolates against S. oryzae: Firstly, the single highest concentration $1 \times 10^{8}$ conidia

Table 1. Sampling Sites, Isolation host and Geographical location of EPF used in study.

\begin{tabular}{|c|c|c|c|c|c|}
\hline Fungal species & Isolate code & Origin & Isolation host & Altitude & Year \\
\hline Metarhizium robertsii & Qin -08 & $\begin{array}{l}\text { FNNR, Qinling Mountains } \\
\text { Southwest Shaanxi province, } \\
\text { China }\end{array}$ & $\begin{array}{l}\text { Soil selective } \\
\text { medium }\end{array}$ & $\begin{array}{l}107^{\circ} 40^{\prime} 21^{\prime} \mathrm{E}, 33^{\circ} 34^{\prime} 12^{\prime} \mathrm{N} \\
(1000 \mathrm{~m})\end{array}$ & 2015 \\
\hline M. anisopliae & Qin- 13 & -do- & -do- & $\begin{array}{l}107^{\circ} 47^{\prime} 14^{\prime \prime} \mathrm{E}, 33^{\circ} 39^{\prime} 79^{\prime \prime} \mathrm{N} \\
(2000 \mathrm{~m})\end{array}$ & 2015 \\
\hline M. pingshaense & Qin-18 & -do- & -do- & $\begin{array}{l}107^{\circ} 55^{\prime} 13^{\prime \prime} \mathrm{E}, 33^{\circ} 45^{\prime} 81^{\prime \prime} \mathrm{N} \\
(3000 \mathrm{~m})\end{array}$ & 2015 \\
\hline M. robertsii & ME-38 (LT-178 & $\begin{array}{l}\text { Sichuan province, (Bazhong, } \\
\text { Ling Ton) China }\end{array}$ & $\begin{array}{l}\text { Bait insect method } \\
\text { (mealworm larvae, } \\
\text { Tenebriomolitor }\end{array}$ & $\begin{array}{l}30^{\circ} 15^{\prime} 80^{\prime \prime} \mathrm{N}, 100^{\circ} 58^{\prime} 67 \\
\mathrm{E}(3380 \mathrm{~m})\end{array}$ & 2016 \\
\hline Isaria cateniannulatus & ME-33 (ILT-01) & $\begin{array}{l}\text { Sichuan province, (Bazhong, } \\
\text { Ling Ton) China }\end{array}$ & -do- & $\begin{array}{l}30^{\circ} 15^{\prime} 80^{\prime \prime} \mathrm{N}, 100^{\circ} 58^{\prime} 67^{\prime \prime} \mathrm{E} \\
(3380 \mathrm{~m})\end{array}$ & 2016 \\
\hline Isaria cateniannulatus & Yulin-5 (IYL-01) & China: Shaanxi: Yu Lin & -do- & $\begin{array}{l}38^{\circ} 32^{\prime} 99^{\prime \prime} \mathrm{N}, 109^{\circ} 70^{\prime} 45^{\prime \prime} \mathrm{E} \\
(1400 \mathrm{~m})\end{array}$ & 2016 \\
\hline Beauveria bassiana & Qin-21 & $\begin{array}{l}\text { FNNR, Qinling Mountains } \\
\text { Southwest Shaanxi province, } \\
\text { China }\end{array}$ & -do- & $\begin{array}{l}33^{\circ} 39^{\prime} 79^{\prime \prime} \mathrm{N}, 107^{\circ} 47^{\prime} 14^{\prime \prime} \mathrm{E} \\
(1600 \mathrm{~m})-\end{array}$ & 2015 \\
\hline
\end{tabular}


$\mathrm{ml}^{-1}$ was tested for pathogenicity (virulence). Two methods of fungus application were studied: 1 - The immersion or dip method, and 2- An application with food mixture. In both methods, the test insects and food were immersed for one minute into the conidial suspension of 5-ml and the excess of conidial excessive suspension were removed by putting the test insects and a food on a sterilize filter paper (Dong yang, China). All the insects, treated in the independent biological repeats were later shifted to WD9-3.5-cm petri plates (Zhejiang Plasmid Medical Technology Co., Ltd., China). All petri plates were settled under the complete randomized design (CRD) and were kept under the Standard climatic chamber environment of $26 \pm 2^{\circ} \mathrm{C}, 80 \pm 7 \% \mathrm{RH}$ with photo phase duration of 12-h:12-h (L: D). All plates were partially sealed with plastic solution tape to avoid the interference of insects. The control adults were treated with sterilized $\mathrm{dd}_{2} \mathrm{O}$. Mortality data were recorded every 24 hours for 14 days.

Virulence assay of EPF against S. oryzae: Based on results of the above-mentioned initial Pathogenicity assay, the isolates that showed the highest mortality were selected for further evaluation of their virulence against the $S$. oryzae. Four different concentrations of conidia were used for each isolate i.e., $1 \times 10^{4}, 1 \times 10^{5}, 1 \times 10^{6}$ and $1 \times 10^{7} \mathrm{ml}^{-1}$. Sterilized $\mathrm{ddH}_{2} \mathrm{O}$ aqueous solution was used for control. For the virulence test, an immersion method was used following the same procedures, 5-ml conidial suspensions. Fifteen Sitophilus oryzae adults were used for every replication and the mortality data were recorded for 24-hours each up to 15days. Mean survival period for each isolate at each concentration was also determined.

Statistical analysis: All the experimental assays in this study were performed by using thrice biological repeats of each fungal isolate under Complete randomized design (CRD) Mortality data were recorded. An (ANOVA) Analysis of variance was used to examine the significant differences statistically within the tested isolates. Obtained data was analyzed statistically by using SAS 13.2. Probit analysis was used to calculate the mean survival times (MST). All required graphs were prepared by using excel software.

\section{RESULTS}

Fungal Isolates tested by Immersion Method at Single Concentration Bioassay: The results presented in (Fig.1) showed that all the isolates differed significantly $(\mathrm{P} \leq 0.03)$. The mortality of the test insect was ranged from 40.2 to 100 percent. The treatments ME-33 and Beauveria bassiana (Qin$21)$ showed the highest mortality $(100 \%)$ and did not show significant difference with Qin-18 (91.66\%). Qin-18 also showed non-significant variation with those of ME-38 $(88.22 \%)$ and Qin-13 (86.66\%). The later mentioned treatments were also at par statistically with Qin-8 (68.5\%) and found to be intermediate. The lowest mortality was observed in Yulin-5 (40.2\%) and differed significantly from all the treatments. The treatments Beauveria bassina (Qin21), ME-33 and Qin-18 proved to be the most effective while Yulin-5, the least.

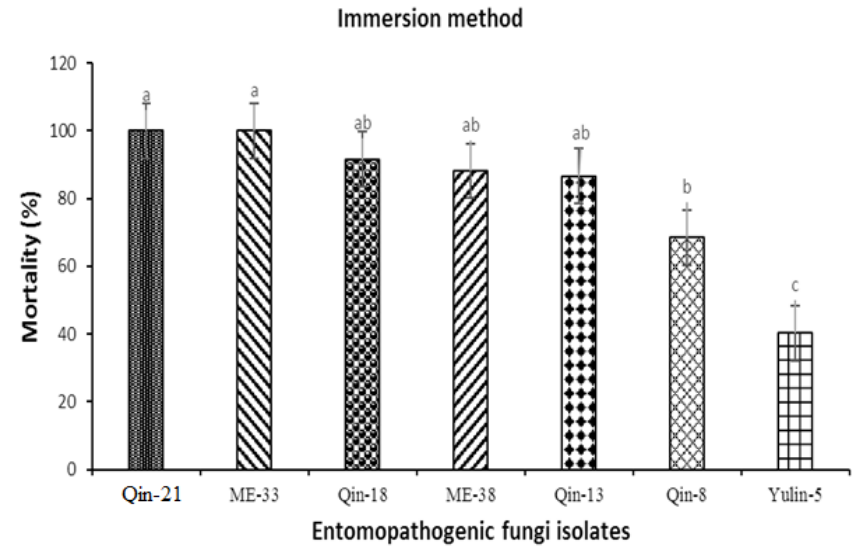

Figure 1. Mortality $\%$ of $S$. oryzae adults tested to immersion method at $1 \times 10^{8}$ conidia $\mathrm{ml}^{-1}$.

Fungal Isolates tested via Food Mix Method at Single Concentration Bioassay: Significant difference ( $\mathrm{P} \leq 0.002)$ was found to exist among treatments (Fig.2). Beauveria bassiana (Qin-21) showed the highest mortality (100\%) of $S$. oryzae and was at par statistically with those of observed in ME-33 and Qin-18 showing pest mortality 98.00 and $84.16 \%$, respectively. The lowest mortality $(32.49 \%)$ was found in Yulin-5 and did not show significant variation with those of found in ME-38 (33.33\%), Qin-8 (51.8\%) and Qin-13 (54.1\%). The treatment Qin-18 was also at par statistically with Qin-8 and Qin-13. Conclusively, Beauveria bassiana (Qin-21) ME-33 and Qin-18 were the most effective while Yulin-5 and Qin-8 the least against S. oryzae. Qin-13 and Qin8 were classified as intermediate.

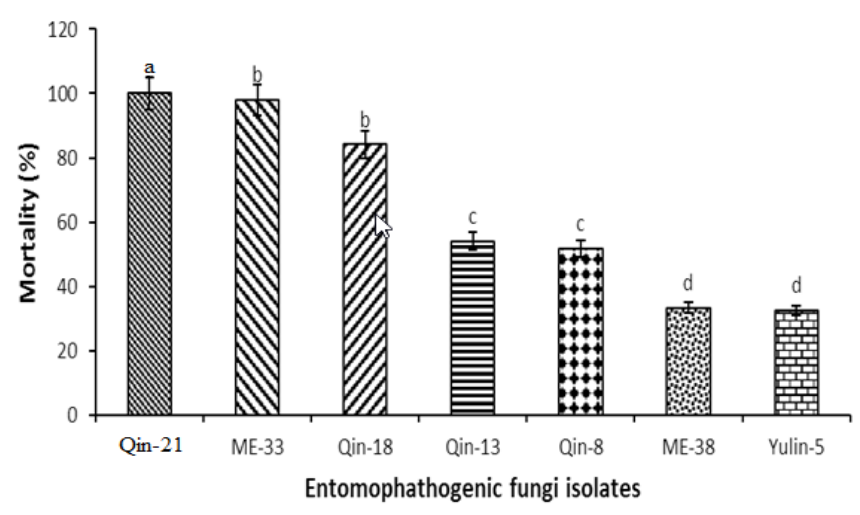

Figure 2. Mortality (\%) of $S$. oryzae adults exposed to food mix method at $1 \times 10^{8}$ conidia $\mathrm{ml}^{-1}$.

Comparison of Immersion and Food Mix Fungal Isolates: The results (Fig. 3) revealed that significantly ( $\leq 0.001)$ maximum mortality $(100 \%)$ of the pest was found in 
Beauveria at both application methods and was at par statistically with those of observed in ME-33 (100\%) at immersion method. The lowest mortality of the pest was observed in Yulin-5 at both methods compared with the remaining pathogens. Immersion method showed higher mortality of the pest in all the isolates as compared to food mixed method.

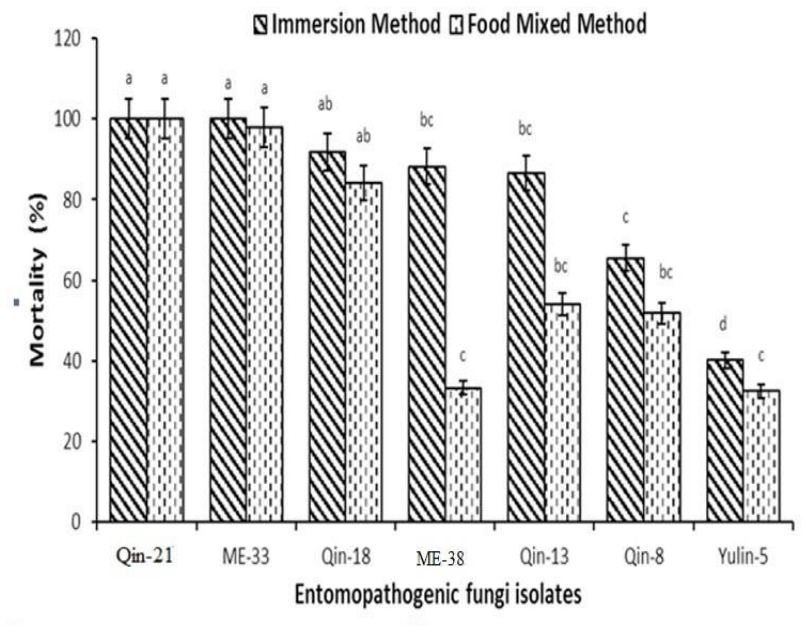

Figure 3. Mortality (\%) of $S$. oryzae adults tested to immersion and food mix method at conidial concentration of $1 \times 10^{8}$.

Multiple concentration bioassays: As per initial screening assays, most effective fungal isolates against $S$. oryzae screened out from single concentration bioassay test were studied for multiple concentration bioassays by immersion method. The results revealed significant variation $(\mathrm{P} \leq 0.001)$ among different concentrations in all the fungal isolates (Fig. 4, 5 and 6). Higher conidial concentrations resulted in maximum mortality of the pest as compared to lower concentrations in all the fungal isolates. The observed mortality of the pest ranged from 44.44 to $80.00,35.56$ to 100 and 40.00 to 64.64 percent at conidial concentration $1 \times 10^{4}$ to $1 \times 10^{7}$ in Beauveria bassiana (Qin-21), ME-33 and Qin-18, respectively. The results presented in Table 1 revealed that ME-33 showed less $\mathrm{LT}_{50}$ i.e., 3.63 days with a range of 3.41 to 3.83 days at higher conidial concentration. The comparison of different isolates (Fig.7 and Table 2) revealed that ME-33 was found to be the most reliable fungal isolate to use against S. oryzae at $1 \times 10^{7}$ conidial concentration compared with the other isolates. All the isolates; however had a potential to control the pest even at lower conidial concentrations by immersion method.

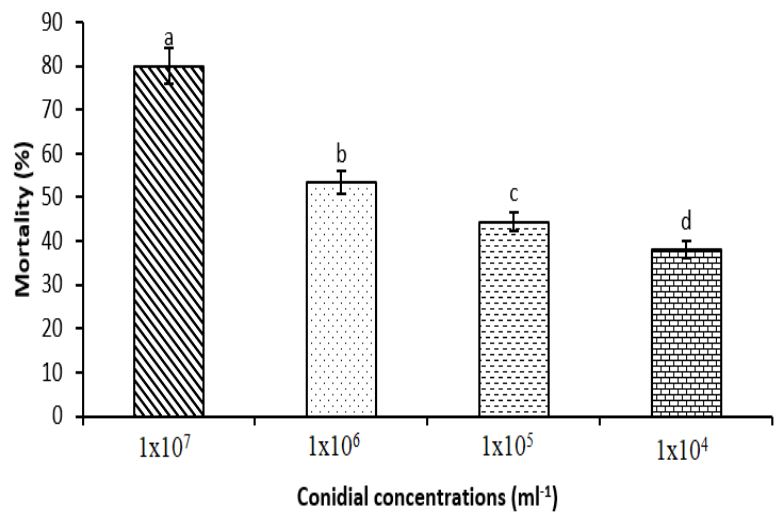

Figure 4. Mortality (\%) of $S$. oryzae adults tested to Beauveria bassiana at different concentrations.

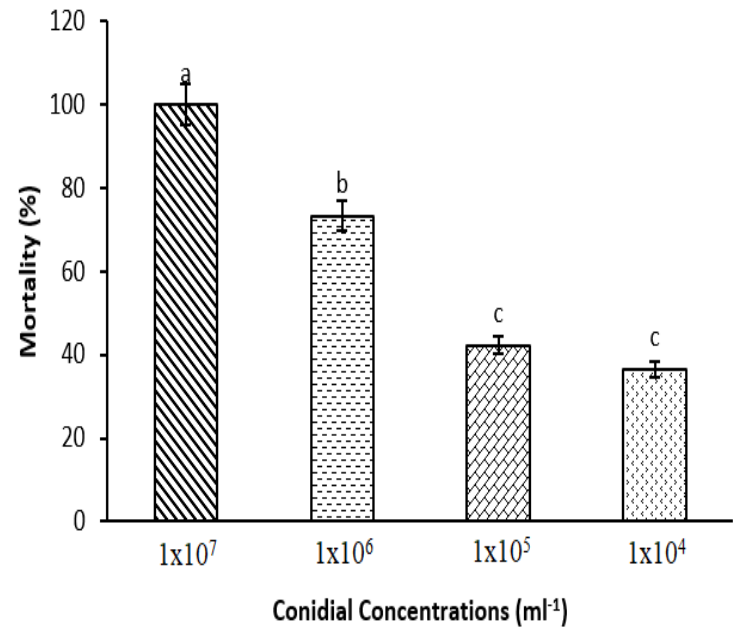

Figure 5. Mortality (\%) of S.oryzae adults tested to ME33 at different conidial concentrations.

Table 2. Comparative $\mathbf{L T}_{50}$ at various conidial concentrations in selected virulent EPF isolates.

\begin{tabular}{|c|c|c|c|c|c|c|c|c|c|}
\hline \multirow{3}{*}{$\begin{array}{l}\text { Conidial } \\
\text { Conc. } \\
\left(\mathrm{ml}^{-1}\right)\end{array}$} & \multicolumn{3}{|c|}{ (Qin-21) } & \multicolumn{3}{|c|}{ (ME-33) } & \multicolumn{3}{|c|}{ (Qin-18) } \\
\hline & \multirow[t]{2}{*}{ Percentile } & \multicolumn{2}{|c|}{ 95\% Fiducial CI } & \multirow[t]{2}{*}{ Percentile } & \multicolumn{2}{|c|}{ 95\% Fiducial CI } & \multirow[t]{2}{*}{ Percentile } & \multicolumn{2}{|c|}{$95 \%$ Fiducial CI } \\
\hline & & Lower & Upper & & Lower & Upper & & Lower & Upper \\
\hline $1 \times 10^{7}$ & 4.17 & 3.79 & 4.53 & 3.6 & 3.41 & 3.83 & 8.5 & 7.96 & 9.30 \\
\hline $1 \times 10^{6}$ & $11.52 \pm 0.64$ & 10.40 & 13.01 & $6.40 \pm 0.21$ & 5.98 & 6.82 & $13.54 \pm 0.79$ & 12.19 & 15.41 \\
\hline $1 \times 10^{5}$ & $17.82 \pm 1.65$ & 15.18 & 22.05 & $16.87 \pm 1.47$ & 14.50 & 20.61 & $16.29 \pm 1.39$ & 14.03 & 19.80 \\
\hline $1 \times 10^{4}$ & $19.78 \pm 1.92$ & 16.75 & 24.78 & $20.32 \pm 2.10$ & 17.05 & 25.90 & $19.24 \pm 1.77$ & 16.44 & 23.82 \\
\hline
\end{tabular}




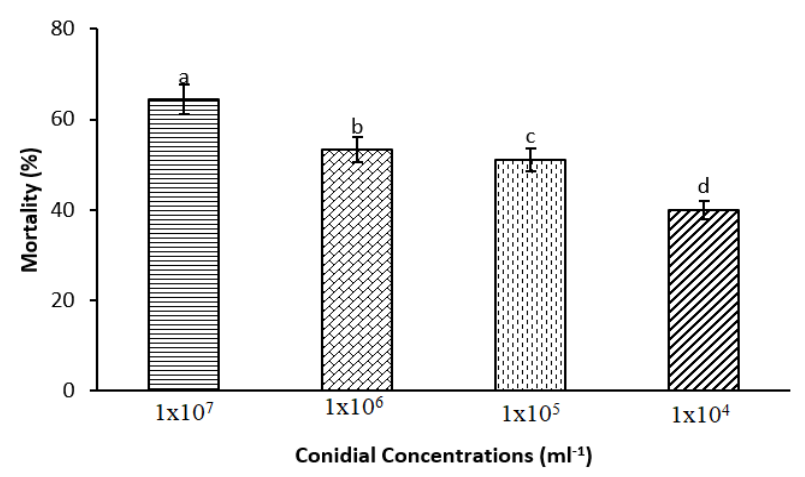

Figure 6. Mortality (\%) of S. oryzae adults exposed to Qin-18 at different conidial concentrations.

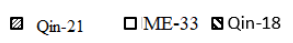

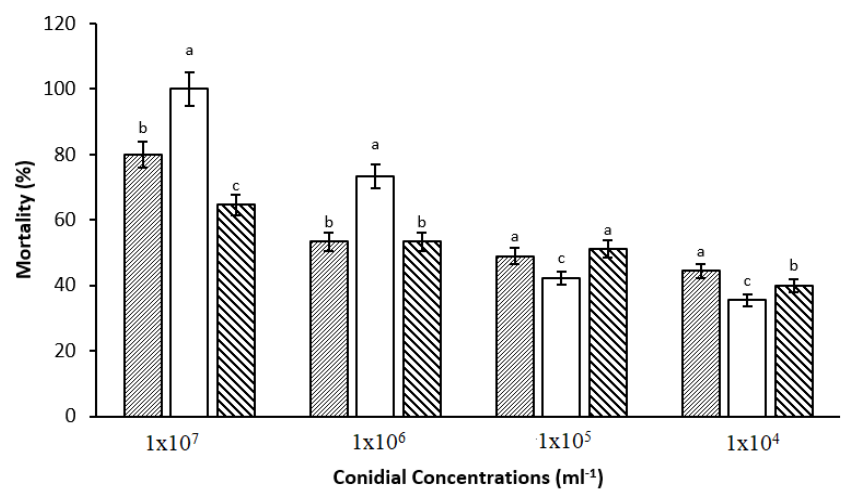

Figure 7. Mortality (\%) of $S$. oryzae adults exposed to three different fungal isolates at different conidial concentrations.
$\boldsymbol{L T}_{50}$ at various conidial concentrations: The results presented in Table. 2 reveals that ME-33 at conidial dose $1 \times 10^{7}$ was the most effective showing minimum $\mathrm{LT}_{50}$ i.e. 3.63 days. The fiducial CI at $95 \%$ ranged from 3.41 to 3.83 . The $\mathrm{LT}_{50}$ values increased on decreasing the conidial concentration in all the isolates. The application of Qin-18 resulted in minimum effect on the pest as it inclined longer period to the pest for its survival with fiducial CI range from 7.96 to 9.30 at the highest conidial concentration. The virulent ME-33 at highest conidial concentration performed the best in controlling the pest as compared to (Qin-21) and (Qin-18). Thus ME-33 is recommended at conidial dose of $1 \times 10^{7} \mathrm{ml}^{-}$ ${ }^{1}$ for the effective control of the pest under study and suggested to include this in IPM tactics.

\section{DISCUSSION}

In-vitro, studies were carried out to determine the comparative virulence of seven entomopathogenic isolates against $S$. oryzae on stored rice at single conidial concentration i.e., $1 \times 10^{8} \mathrm{ml}^{-1}$ by food mixed and immersion methods. Beauveria bassiana (Qin-21) isolates, (ME-33) and (Qin-18) isolates were found to be the most effective and based on the high insect mortality and low MST values among both methods of application, isolates were selected for further studies at multiple conidial concentrations i.e., $1 \times 10^{4}$ to $1 \times 10^{7}$ by immersion method. The results of this study demonstrated significant variation among the different fungal isolates and genera. S. oryzae adults were susceptible to EPF isolates that
ME-33
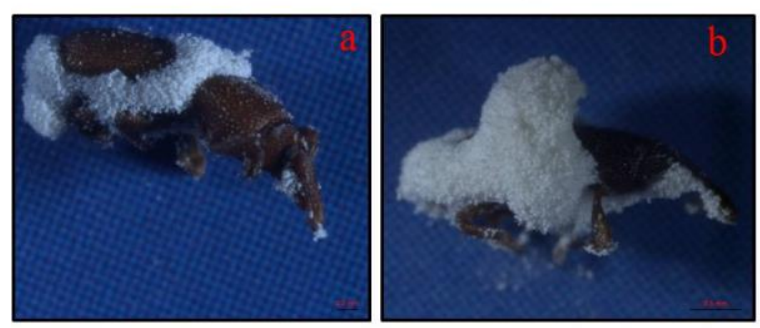

d

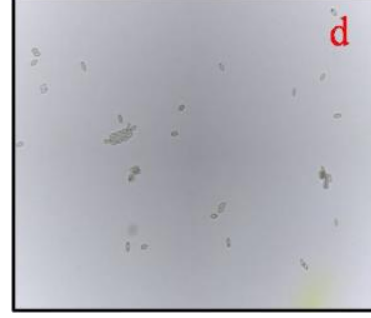

Qin-21

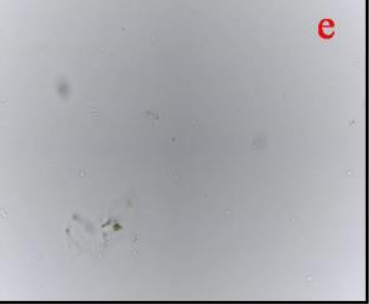

Qin-18

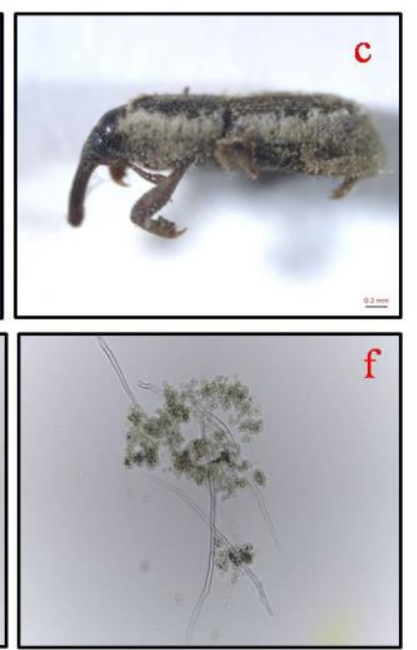

Figure 8. Fungal mycosis symptoms on the beetle cadavers of three different genera of EPF, isolates, Isaria cateniannulatus ME-33 ( ILT-01), B.bassiana (Qin-21) and M. pingshaense (Qin-18). Mycosis photos were taken by advance stereomicroscope system (Discovery V20, Zeiss; CCD,Axio,ICC5,ZEISS; and Leica 205C,Germany, (a-c);Conidiospores photos of the highly virulent isolates were taken by the SOPTOPEX20, Biological microscope, Shanghai Jonchang Co.,Ltd (d-f). 
were tested in this study. Toxicity of the isolates and its possible pathogenicity level depend on the bioassay conditions as well as the host immune system. In many of these type of studies, effective results were observed when stored grains were treated with entomopathogenic fungi, particularly B. bassiana and $M$. anisopliae. Similarly, this study also demonstrates significant results for the pathogenic isolates, which were very effective and responsible for $S$. oryzae mortalities (Athanassiou et al., 2007, 2008; Hansen et al., 2007; Batta, 2013), but they have different virulence levels. Furthermore, our results indicate difference in susceptibility among different fungi against $S$. oryzae. ME33, Qin-21 and Qin-18 were found to be more effective among all tested fungi against $S$. oryzae. (Batta, 2016a.b; Batta, 2012), described the high degree of susceptibility of two different insects against B. bassiana and $S$. maize and found similar results in different fungus against larvae of Plutella xylostella. Consequently, our results are in agreement with earlier study by (Dal et al., 2006), exposed that differences in a fungal ability to reduce the host defense mechanism lead to treatments with a higher $\mathrm{LT}_{50}$ as well prolong the insects' survival. The variation observed in the isolates, $\mathrm{LT}_{50}$ values likely reflects the physiological and genetic differences among these fungal isolates.

The present study revealed that, conidial concentration was the primary factor which keeping up the "speed of kill" of the subjected insects in majority of observations. Despite the fact that there was no prior study available that compared these seven fungi against $S$. oryzae. Previous reports suggested that B. bassiana and $M$. anisopliae might be more effective than other isolates. Indeed, (Talaei et al., 2006; Batta et al., 2010; Batta, 2016a) reported that there is no reliable indicator for the virulence that shows the original host is specific for the specific fungus. Ramanujam et al. (2015) reported that the isolates PPRCH-HH and PPRC-4 showed the high pathogenicity against the stem borer Chilo partellus. In some other studies it has been reported that most virulent isolates are isolated from closely related host or the same place (Batta and $\mathrm{Abu}, 2005)$. It is also agreed that some fungus has broad host range like $B$. bassiana and $M$. anisopliae and their pathogenicity also varies as per their host. Subsequently, (Batta, 2007; Addis and Tadele, 2009) reported an increasing trend in $M$. anisopliae and B. bassiana that pathogenicity drives through the habitat selection. Therefore, the current results revealed that the selection of the potential isolates would not be restricted to isolates of fungi from the sole host mass. Entomopathogenic fungi isolates, ME-33 (ILT-01) (Isaria cateniannulatus) was consistently more virulent than Beauveria bassiana (Qin-21) and (Qin-18) M. pingshaense. Thus, considering the low mean survival time MST range, these fungi isolates could be reflected more pathogenic amongst all tested isolates against the rice weevil management Program. Maximum mortality rate was detected on the high conidial concentrations of $1 \times 10^{8}$ and $1 \times 10^{7}$ conidia/ml which shows that more number of conidia with the high concentrations as well as adhere chances are increased. Mortality was observed at all the concentrations of each isolate but this mortality is limited which ranged from $35.5 \%$ to $40 \%$ at lower concentrations and this low mortality is responsible for slow development of disease or infection which was the effect of low dose application (Batta, 2012). In the present study, high conidial concentration caused the mortality of insect in a short time (3.41 to 8.58 days) whereas, low conidial dose took a longer period (19.24 to 20.32 days). These findings confirm that the results of (Batta et al., 2010), who stated that the concentrations applied with high conidia rates caused the mortality in a short time but on the other hand doses with low conidial concentrations may take two or more weeks to kill the test organisms. Different Beauveria bassiana isolates Pathogenicity was evaluated against the corn weevil by (Addis and Tadele, 2009; Cherry et al., 2005) reported that among these ten isolates one isolates showed higher mortality $(88 \%)$ within 8 -days at the low concentration of $1 \times 10^{4}$ conidia $\mathrm{ml}^{-1}$. In some other studies high dose requirement is reported against T. Castenum and Callosobruchus maculatus (Clare et al., 2016). However, in some other studies low concentration doses against Stored Grain Beetles were required (Mehmet et al., 2016). George et al. (2018) examined that B. bassiana isolates were much lethal against $S$. zeamais only at high concentrations of $1 \times 10^{7}$ conidia $\mathrm{ml}^{-1}$ and reported that pathogenicity varies within the isolates was superficial.

The method of application as well as fungal formulation was the most important factor in its efficacy against $S$. oryzae adults. Previous studies provide interesting information on this issue. For example, Cherry et al. (2005) reported 100\% mortality of C.maculatus adults dipped for 5 seconds into a conidial suspension of $M$. anisopliae and B. bassiana after 6 and 8 days of introduction. Furthermore, it has been reported by (George et al., 2018), stated $S$. zeamais adults which were dipped into certain isolates of $B$. bassiana suspension for 5 seconds suffer $100 \%$ mortality after only 4 days after application time. Nearly similar results were also found for $S$. oryzae treated with certain $B$. bassiana and $M$. anisopliae isolates. As for the application methods examined here, direct application (Immersion method) of the fungus on insect bodies is much successful compare to contact of insects with the fungi isolates which is applied on the food substrate.

Conclusion: The present study is novel tactic linking the use of indigenous isolates. Mortality results were found to be directly related to the conidial concentrations as well as the exposure time. Among the selected isolates, the highest mortality of 100, 80 and $64.64 \%$ was observed on the conidial dose of $1 \times 10^{7}$ for the isolates ME-33, Qin-21 and the Qin-18. Tested isolates could be suggested as promising candidates in terms of virulence and pathogenicity for the integrated pest management program against S.oryzae and the local pest species of the stored commodities. Further research needed to 
develop the myco-insecticides for the control of different pests. Considering different aspects like mass productions, storage, formulations, spectrum of activities against the nontarget organisms under the various environmental conditions.

Acknowledgements: We are highly thankful to National Natural Science Foundation of China as this study was funded by NSFC grant (31670659) and National key research and development project (2018YFD0600202-03).

\section{REFERENCES}

Addis, T. and T. Tadele. 2009. Susceptibility of Sitophilus zeamais (mostch.) (Coleoptera: Curculionidae) to Beauveria bassiana and Metarhizium anisopliae. Ethiop. J. Sci. 32:21-28.

Athanassiou, C.G., N.G. Kavallieratos, B.J. Vayias, J.B. Tsakiri, N.H. Mikeli, C.M. Meletsis and Z. Tomanovic. 2008. Persistence and efficacy of Metarhizium anisopliae (Metschnikoff) Sorokin (Deuteromycotina: Hyphomycetes) and diatomaceous earth against Sitophilus oryzae (L.) (Coleoptera: Curculionidae) and Rhyzopertha dominica (F.) (Coleoptera: Bostrychidae) on wheat and maize. Crop Prot. 27:1303-1311.

Athanassiou, C.G., T. Steenberg and N.G. Kavallieratos. 2007. Insecticidal effect of diatomaceous earth applied alone or in combination with Beauveria bassiana and beta cyfluthrin against Sitophilus granarius on stored wheat. IOBC/WPRS Bull. 30:25-36.

Barra, P., L. Rosso, A, Nesci and M. Etcheverry. 2013. Isolation and identification of entomopathogenic fungi and their evaluation against Tribolium confusum, Sitophilus zeamais, and Rhyzopertha dominica in stored maize. J. Pest Sci. 86:217-226.

Batta, Y. and S.D. Abu. 2005. A study of treatment effect with Metarhizium anisopliae and four types of dusts on wheat grain infestation with red flour beetles (Tribolium castaneum Herbst, Coleoptera: Tenebrionidae). Islam U. Gaza. J. 13:11-22.

Batta, Y. 2013. Efficacy of endophytic and applied Metarhizium anisopliae (Metch.) Sorokin (Ascomycota: Hypocreales) against larvae of Plutella xylostella L. (Yponomeutidae: Lepidoptera) infesting Brassica napus plants. Crop Protec. 44:128 134.

Batta, Y.A. 2005. Control of lesser grain borer (Rhyzopertha dominica (F.), Coleoptera: Bostrichidae) by treatments with residual formulations of Metarhizium anisopliae (Metschnikoff) Sorokin (Deureromycotina: Hyphomycetes). J. Stored-Prod. Res. 41:221.

Batta, Y.A. 2007. Biocontrol of almond bark beetle (Scolytus amygdali Geurin-Meneville, Coleoptera: Scolytidae) using Beauveria bassiana (Bals.) Vuill. (Deuteromycotina: Hyphomycetes). J. Appl. Microbiol. 103:1406-1414.
Batta, Y.A. 2008. Control of main stored-grain insects with new formulations of entomopathogenic fungi in diatomaceous earth dusts. Int. J. Food. Eng. 4:1-16.

Batta, Y.A. 2012. The first report on entomopathogenic effect of Fusarium avenaceum (Fries) Saccardo (Hypocreales: Ascomycota) against rice weevil (Sitophilus oryzae L., Curculionidae: Coleoptera). J. Entomol. Acarol. Res. 44:51-55.

Batta, Y.A. 2016a. Invert emulsion method of preparation and application as proper formulation of entomopathogenic fungi. Methods X. 3:119-127.

Batta, Y.A. 2016b. Recent advances in formulation and application of entomopathogenic fungi for biocontrol of stored-grain insects. Biocontrol Sci. Technol. 26:11711183.

Batta, Y.A., G. Murdoch and S. Mansfield. 2010. Investigations into the formulation and application of entomopathogenic fungi against larvae of yellow meal worm (Tenebrio molitor L., Coleoptera: Tenebrionidae). Gen. Appl. Entomol. 39:5-8.

Boyer, S., H. Zhang and G Lemperiere. 2012. A review of control methods and resistance mechanisms in storedproduct insects. Bull. Entomol. Res. 102:213-229.

Butt, T.M., C. Wang, F.A. Shah and R. Hall. 2006. Degeneration of entomogenous fungi. In: Eilenberg, J.Hockkanen, H.M.T. (Eds.). An ecolog. societal approach to biolog. Control;pp. 213-226.

Cherry, A.J., P. Abalo and K. Hell. 2005. A laboratory assessment of the potential of different isolates of the entomopathogenic fungi Beauvaria bassiana (Balsamo) Vuillemin and Metarhizium anisopliae (Metschnik off) to control Callosobruchus maculatus (F.) (Coleoptera: Bruchidae) in stored cowpea. J. Stored-Prod Res. 41:295309.

Clare, S., S. Freya, N. Adam, P. Olivier and D. Aoife. 2016. Improving Efficacy of Beauveria bassiana against Stored Grain Beetles with a Synergistic Co-Formulant. Insects. 7:1-14.

Dal, B., G. Padin, S.P. Juarez and N.B. Pedrini. 2006. Biocontrol of Acanthoscelides obtectus and Sitophilus oryzae with diatomaceous earth and Beauveria bassiana on stored grain. Biocontrol Sci. Tech. 16:215-220.

George, N.M., C.I. bata and S.I. David. 2018. The potential for using entomopathogenic nematodes and fungi in the management of the maize weevil, Sitophilus zeamais (Motschulsky) (Coleoptera:Curculionidae) Biol. Control. 125:39-43.

Hansen, L.S and T. Steenberg. 2007. Combining larval parasitoids and an entomopathogenic fungus for biological control of Sitophilus granarius (Coleoptera: Curculionidae) in stored grain. Biol. Control. 40:237242.

Hertlein, M.B., G.D. Thompson, B. Subramanyam and C.G. Athanassiou. 2011. Spinosad a new natural product for stored grain protection. J. Stored Prod Res. 47:131-146. 
Hibbett, D.S., M, Binder., J.F. Bischoff, M. Blackwell and P.F Cannon. 2007. A higher-level phylogenetic classification of the fungi. Mycol. Res. 111:509-547.

Inglis G, D, Johnson, M. Goettel. 1997. Field and laboratory evaluation of two conidial batches of Beauveria bassiana (Balsamo) Vuillemin against grasshoppers. Can Entomol. 129:171-186.

Kaur, S., A. Thakur and M. Rajput. 2014. A laboratory assessment of the potential of Beauveria bassiana (Balsamo) Vuillemin as a biocontrol agent of Corcyra cephalonica Stainton (Lepidoptera: Pyrallidae). J. Stored Products Res. 59:185-189.

Kavallieratos, N.G., C.G. Athanassiou, M.M Aountala and D.C. Kontodimas. 2014. Evaluation of the entomopathogenic fungi Beauveria bassiana, Metarhizium anisopliae, and Isaria fumosorosea for control of Sitophilus oryzae. J. Food Protec. 1:4-17.

Leger, S.T and RJC Wang. 2010. Genetic engineering of fungal biocontrol agents to achieve efficacy against insect pests. Appl. Microbiol. Biot. 85:901-907.

Liu, R.H. 2007. Whole grain phytochemicals and health. J. Cereal. Sci. 46:207-219.

Lord, J.C. 2007. Enhanced efficacy of Beauveria bassiana for red flour beetle with reduced moisture. J. Econ. Entomol. 100:1071-1074.

Maina, U.M., I.B. Galadima, F.M. Gambo and D. Zakaria. 2018. A review on the use of entomopathogenic fungi in the management of insect pests of field crops. J.E.Z.S. $6: 27-32$.

Mandira, K.B., R.B. Upendra, M. Abolfazl, J.N. Feng, W. Dun. 2018. Pathogenicity and virulence of the entomopathogenic fungi depend on selective suppression of anti-oxidative and detoxification enzymes in Tenebrio Molitor (Coleoptera: Tenebrionidae) larvae. Biochem. Cell. Arch. 18:861-87.

Mehmet KER, Hasan T, Ceyda K, Cebrail B, Ali AI. 2016. Occurrence of entomopathogenic fungi on insect pests of stored wheat and maize in Central and South Anatolia in Turkey. Türk. entomol. derg. 40 :249-263.

Nguyen, T.T., P.J. Collins, T.M Duong, D.I. Schlipalius and P.R Ebert. 2016. Genetic conservation of phosphine resistance in the rice weevil Sitophilus oryzae (L.). J. Hered. 107:228-237.

Ortiz-Urquiza, A and N.O. Keyhani. 2013. Action on the surface: entomopathogenic fungi versus the insect cuticle. Insects. 4:357-374.

Pedrini, N., Crespo, R., Juárez, M.P. 2007. Biochemistry of insect epicuticle degradation by entomopathogenic fungi. Compar Biochem Physiol C: Toxicol. Pharmacol. 146:124-137.

Phillips, T.W and J.E. Throne. 2010. Biorational approaches to managing stored-product insects. Ann. Rev. Entomol. 55:375-397.
Ramanujam, B., B. Poornesha, K.R. Yatish and S. Renuka. 2015. Evaluation of Pathogenicity of Different Isolates of Metarhizium anisopliae (Metchnikoff) Sorokin against maize stem borer, Chilo partellus (Swinhoe) using laboratory bioassays. Biopestic. Int. 11:89-95.

Ramanujam, B., R. Rangeshwaran, G. Sivakmar, M. Mohan and M.S Yandigeri. 2014. management of insect pests by microorganisms. P. Indian Natl. Sci. Acad. 80:455-471.

Rojht, H., A. Horvat, C.G. Athanassiou, B.J and Vayias, Z. Tomanovic and S. Trdan. 2010. Impact of geochemical composition of diatomaceous earth on its insecticidal activity against adults of Sitophilus oryzae (L.) (Coleoptera: Curculionidae). J. Pest Sci. 83:429-436.

Sanchez-Rodriguez, A.R., S.R. Diaz, A.M. Zamarreno and E. Quesada. 2017. An endophytic Beauveria bassiana strain increases spike production in bread and durum wheat plants and effectively controls cotton leaf worm (Spodoptera littoralis) larvae. Biolog. Control. doi: http://dx.doi.org/10.1016/j.biocontrol.2017.01.012 (Accepted).

Stejskal, V., J. Hubert, R. Aulicky and Z. Kucerova. 2015. Overview of present and past and pest-associated risks in stored food and feed products: European perspective. J. Stored-Prod. Res. 64:122-132.

Stephou, V.K., S.E. Tjamos, E.J. Paplomatas and C.G Athanassiou. 2012. Transformation and attachment of Beauveria bassiana conidia on the cuticle of Tribolium confusum and Sitophilus oryzae in conjunction with diatomaceous earth. J. Pest Sci. 85:387-394.

Tadele, T and K.L Pringle. 2007. Biological control of the spottedstem borer Chilopartellus (Swinhoe) (Lepidoptera:Crambidae) with the Entomopathogenic fungi, Beauveria bassiana and Metarhizium anisopliae. SINET. Ethiopian. J. Sci. 30:65-70.

Talaei, H.R., P.A. Kharazi, M. Goettel and J. Mozaffari. 2006. Germination polarity of Beauveria bassiana and its possible correlation with pathogenicity. J. Invertebr. Pathol. 94:102-107.

Tadesse, T.M., B. Subramanyam. 2018. Efficacy of filter cake and Triplex powders from Ethiopia applied to wheat against Sitophilus zeamais and Sitophilus oryzae. J. Stored. Prod. Res. 79:40-52.

Yacoub, A.B. 2018. Efficacy of two species of entomopathogenic fungi against the stored-grain pest, Sitophilus granarius L. (Curculionidae: Coleoptera), via oral ingestion. Egypt. J. Biol. Pest Co. Vol 19:28-44.

Yacoub, A.B., G.K. Nickolas. 2017. The use of entomopathogenic fungi for the control of stored-grain insects. Int. J. Pest Manage. Vol 64:77-87.

Zhang, Y.J., M.G. Feng, Y.H. Fan, Z.B. Luo, X.Y. Yang, D., $\mathrm{Wu}$ and Y.A. Pei. 2008. Cuticle degrading protease (CDEP-1) of Beauveria bassiana enhances virulence. Biocontr. Sci. Technol. 18:551-563. 